\title{
Hacking the representative system through deliberation? The organization of the Agora party in Brussels
}

\author{
Nino Junius ${ }^{1} \cdot$ Didier Caluwaerts $^{1}$ (D) $\cdot$ Joke Matthieu $^{1} \cdot$ Silvia Erzeel $^{1}$
}

Accepted: 19 November 2021

(C) Springer Nature Limited 2021

\begin{abstract}
Recent years have witnessed the emergence of a variety of deliberative practices in the organization and activities of political parties. What remains unclear, however, is how parties can promote deliberative democracy in an environment that remains predominantly representative. To investigate this tension, we study the Agora party in Brussels. Agora competed for the first time in the 2019 regional elections in Brussels with the aim of institutionalizing a permanent, randomly selected Citizen's Assembly with legislative power in the Brussels Capital Region and immediately gained a seat in the Brussels Regional Parliament. Based on an in-depth qualitative study including 20 semi-structured interviews with a broad range of party members and document analysis, we study whether and how Agora's organizational structure, i.e. its leadership and centralization, its intra-party democracy, and its organizational resources, allow it to promote deliberative democracy in a representative context. We argue that Agora experiences tensions between its deliberative ideals and its representative means and that there is a looming danger of becoming "just another part" of the system. However, it succeeds in simultaneously rejecting and competing in the representative system by adopting a stratarchical party organization.
\end{abstract}

Keywords Political parties · Party organization · Agora · Deliberative democracy

Nino Junius

nino.junius@vub.be

Didier Caluwaerts

didier.caluwaerts@vub.be

Joke Matthieu

joke.matthieu@vub.be

Silvia Erzeel

silvia.erzeel@vub.be

1 Department of Political Science, Vrije Universiteit Brussel, Pleinlaan 2, 1050 Brussels, Belgium 


\section{Introduction}

Recent years have witnessed the emergence and rise of a variety of deliberative practices in the organization and activities of political parties (Gherghina et al. 2020). Examples include the Danish Alternativet, Demos in Romania, and Code Oranje in the Netherlands. Following the lead of ecologist parties, which have been actively promoting participatory democracy since the 1970s (Frankland et al. 2008; Rihoux 2016), these parties rely on deliberation as a central decision-making principle and propose a fundamentally new way of doing politics. One that is less vote-centric and more talk-centric. Deliberation is therefore not merely co-opted as an add-on to the traditional hierarchical party organization. Instead, these parties rely on the principles and practices of deliberation in an attempt to involve grass-roots members and citizens in an interactive and communicative setting to determine the party's policy positions and organization.

Even though these deliberative practices in political parties have recently been the subject of academic scholarship, the literature has only begun to understand how deliberation is implemented in parties' organizational practice as well as which organizational and strategic challenges this poses (see Gherghina et al. 2020 for a recent overview). In particular, it remains unclear how parties navigate the troubled waters of pursuing their aims of promoting deliberative democracy in an environment that remains predominantly representative. How do they organize effectively to realize their distinct goals? How do they translate their programmatic ideals of deliberation into an organizational party practice? And how do they balance the competing demands of deliberative inclusion and representative efficiency (Ignazi 2018)?

To investigate these questions, we study the Brussels party Agora as it challenges the representative system more explicitly from a deliberative vantage point than any other party we know of. Agora emerged in 2018 and its single programmatic focus was the establishment a permanent, randomly selected deliberative Citizens' Assembly with full legislative power in Brussels. Because the establishment of such an assembly was unlikely in the short-term, Agora decided to 'hack' the representative system from within by competing in the 2019 Brussels regional election in which they won $5.18 \%$ of the votes resulting in one seat in the Brussels Parliament. Using the institutional leverage of their one MP, Agora decided to organize an assembly on its own during the 2019-2024 parliamentary term. The party would use the representative's salary to run an assembly consisting of 89 randomly selected Brussels citizens, ${ }^{1}$ the recommendations of which would be transferred to the parliament through the representative. In other words: Agora's activities in parliament would merely constitute an enactment of the decisions made by the Citizens' Assembly.

Agora constitutes an extreme case of parties promoting deliberative practices. After all, contrary to other parties which rely on deliberation as a means to promoting a substantive party program, Agora considers deliberation both the means and

1 The 89 randomly selected citizens are equal in number to the 89 elected Brussels MPs.

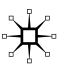


the ends. The party's sole programmatic focus centres on maximizing deliberation both internally and externally to its own organization (Wolkenstein 2018; Barberà and Rodríguez-Teruel 2020; Gad 2020; Vodová and Voda 2020). By studying this particular case, we shed light on how its aim of promoting deliberative practices translates into its organizational features and elaborate on the organizational and strategic tensions that occur. More precisely, we build on the conceptual distinction made by Poguntke et al. (2016) and Scarrow et al. (2017) to study how Agora's deliberative ideals shape three crucial aspects of party organization: their structure regarding leadership and centralization, organizational resources, and intra-party democracy.

Based on an in-depth qualitative study including document analysis and 20 semi-structured interviews with a broad range of party members, we argue that Agora-much like other parties promoting deliberative practices-experiences tensions between its deliberative ideals and its representative means and that there is a looming danger of becoming "just another part" of the system. For the time being, however, Agora is relatively successful in simultaneously rejecting and competing in the representative system by adopting a stratarchical party organization in which the main policy-making powers are attributed to randomly selected citizens without formal ties to the party and in which each supporter has an equal say in the party's internal functioning (Bolleyer 2012; Carty 2004).

We start with a discussion on the relationship between deliberation and political parties and its relation to party organization. Secondly, we discuss the methodology, after which we analyse the case of Agora.

\section{Deliberative practices within parties}

Normative deliberative theory seeks to foster political legitimacy by empowering citizens to engage in an inclusive mutual process of reason-giving on matters of common concern (Bächtiger and Parkinson 2019). Some parties have subscribed to this logic and adopted deliberative practices as part of a broader set of participatory initiatives in response to a legitimacy crisis that has affected, and still affects, political parties in many established democracies (Dalton and Wattenberg 2002; Van Biezen et al. 2012; Van Haute et al. 2018). Even though these practices all involve members and voters in intra-party decision-making, they can serve many goals (Cross and Katz 2013; Pilet and Cross 2014; Rahat and Shapira 2017; Sandri et al. 2015). Some parties have used deliberative or participatory techniques for candidate and leadership selection or intraparty policy development (Barberà and Rodríguez-Teruel 2020; Vodová and Voda 2020). Others have used deliberative means to deliver input on coalition negotiations or determining how the party-in-parliament should vote (Vodova and Voda 2020) through deliberative platforms, local discussion tables or even full deliberative polls. As such, deliberation not only contributes to the legitimacy of the party's internal organization, but it also gives these parties an external strategic advantage within the representative system (Barberà and Rodríguez-Teruel 2020). After all, these parties use deliberation to determine their positions in an inclusive and transparent way and to show that they propose ideas that the general public might also endorse. Those ideas might therefore 
be harder to ignore by other parties which could be portrayed as betraying the informed will of the people.

Even though the reliance on deliberation could give parties a strategic edge, pursuing a deliberative logic in a representative system predominantly ruled by an aggregative logic is not an easy feat. Parties promoting an ideal of rational, respectful, and inclusive discussion have to simultaneously operate in a political arena that is fundamentally at odds with this ideal (Bolleyer 2013; Bennett et al. 2018). They pursue a 'deeper' democracy that surpasses voting but at the same time have to present themselves at elections every couple of years. Moreover, reconciling the 'slow' politics of deliberation with the 'instant' decision-making in highly mediatized politics remains a challenge. Deliberative decision-making is slow and parties adopting this mode of decision-making risk being outpaced and even outsmarted by other parties who might be tempted to co-opt their ideas (Van Spanje 2018).

Even though tensions between deliberative ideals and a representative context are expected, research has not yet shown whether these parties have also translated their deliberative ideals into a new organizational structure. In a recent overview of party organization in a variety of traditional and new parties, Poguntke et al. (2016) find that although deliberation and participation are increasingly used to reinvigorate intra-party democracy, these new initiatives do not fundamentally change the core organizational structure of these parties. Most parties today still organize according to the model of a "subscriber democracy" (Scarrow 2015) or the "representative ideal of the mass party" (Gauja 2013, p. 33) in which (only) fee-paying members can have a say in important party decisions and can hold the party leadership accountable through mostly representative mechanisms.

Hence, new deliberative and participatory initiatives, if adopted, are implemented in largely aggregative and representative party organizations (Wolkenstein 2016). This, in the end, should perhaps come as no surprise, given that democratizing efforts within parties are sometimes paralleled with trends towards more leadership domination, centralization, and party cartelization (Katz and Mair 2018; Wauters 2014). In that sense, they support, rather than challenge, the organizational survival of cartel parties.

Even parties that explicitly endorse deliberation and promote it in their organization experience difficulties in sustaining this in the long run. Podemos and M5S, for instance, started out advocating democratic renewal but became increasingly dominated by their top-down elite (Mosca 2020; Caiani et al. 2021). The question then becomes how Agora, as a party that pushes deliberative ideals and practices to its limits, deals with these tensions at an organizational level. To answer this question, we draw on the conceptual party organization framework made by Poguntke et al. (2016) and Scarrow et al. (2017).

\section{Party organization: structure, intra-party democracy, and resources}

In order to match their deliberative ideals with the representative context, we expect parties to adapt the three central dimensions of party organization distinguished by Poguntke et al. (2016): (1) their structure in terms of leadership and centralization, 
(2) their intra-party democracy, and (3) their organizational resources. It is important to note beforehand that not all dimensions and subdimensions will be equally important for our analysis, especially since these new parties promoting deliberative practices are a relatively new phenomenon. However, in line with Scarrow and Webb's own suggestion (2017, p. 6) we use these dimensions as heuristics for understanding how parties organize.

\section{Structure}

A first dimension of party organization is structure, i.e. the formal organizational lay-out of the party and the distribution of power among the different party entities. To connect the party on the ground with the party in office, most parties establish internal procedures resembling those of representative parliamentary democracy. Therefore, central to the structural dimension of party organization is the presence or absence of mechanisms which limit the power of the party leadership and which allow fee-paying members to hold the party leadership to account.

The structural dimension first of all assesses the autonomy and power of the party leadership. Studies about leadership autonomy emphasize an overall trend towards more leadership domination in recent years, however, with important levels of variation across parties and countries (Passarelli 2015; Poguntke et al. 2016; Schumacher and Giger 2017). In a similar vein, studies looking at the balance of power within parties sometimes notice that parties have become more 'top heavy' (Sandri and Amjahad 2015; Wauters 2014), whereas others notice a move away from hierarchical models of party organizations where power is located at the top of the (central) party towards 'stratarchical' models where power is distributed among central and sub-central party entities (Carty 2004; Bolleyer 2012).

The position of the leadership is always balanced by the position of the other party entities. This touches upon the second structural dimension of party centralization. Centralization tells us whether decisions are made at the central party level (Poguntke et al. 2016). The issue of centralization speaks directly to the distinction between stratarchical and hierarchical forms of party organization. While a hierarchical organization presupposes a vertical chain of command with strong leadership, a stratarchy can be defined as a party organization model which establishes and regulates the interaction between mutually autonomous entities (Bolleyer 2012; Carty 2004; Cross 2018). These entities exercise functionally different competencies that remain interdependent by sharing an overarching strategy and vision (Bolleyer 2012, p. 5). A stratarchy has two main features: distributing power between party entities and separating power in which different entities have different autonomous functional competencies (Cross 2018). In contrast to the power concentration in a hierarchical party model, organizational power in a stratarchy does not rest in one single place. Stratarchies are organized through a kind of central organization but to what extent this entity adopts a centralizing or decentralizing logic depends on efficiency rationales and the organizational philosophy of members (Carty 2004, p. 10). While a stratarchical organization cannot be simply equated with decentralization, the existence of different autonomous entities presupposes a logic of distribution 
and balancing between party entities. In such an organization, Carty argues (2004, p. 21), leadership is "at once both strong and fragile". Leaders enjoy considerable autonomy and command over the party but are also vulnerable to leadership challenges from various entities.

If we assume that Agora practices what it preaches and that its organizational structure reflects its deliberative ideals, then the expectation is that it will impose significant restrictions on the power of the leadership to the advantage of the members, and that it will adopt a decentralized stratarchical structure in which the power of one party entity is balanced by the power of the others. It will not be top-heavy and will not centralize power in the hands of a small party leadership elite.

\section{Intra-party democracy}

In addition to its formal structure, a party also needs to connect with its members, voters, and the general public to generate legitimacy. Party structure is therefore tightly related to the second dimension of party organization which concerns intraparty democracy. Parties seek democratic linkage in different ways and differ in the extent to which, and the ways in which, they extend the right to participate in internal party decision-making to various groups of supporters (Poguntke et al. 2016).

Three questions are central to parties' intra-party democracy: who, how, and to what end. The first one is who to involve and how wide a net the party wants to cast (Scarrow 2015, p. 6). Does the party extend chances for participation to its feepaying members, its voters, or even the general public? The more inclusive a party is, the larger the number of actors that can influence the parties' decision-making process (Hazan and Rahat 2010). In a party, the question of who can be a decisionmaker is tightly related to who the party members are and what kind of membership can be identified in a particular party. Scholars have, however, noted that the nature of party membership is in flux (Scarrow 2015). The divide between members and non-members has become increasingly blurred (e.g. Fisher et al. 2014). Parties are attempting to re-engage their supporters and members by constructing varying notions of membership (Gauja 2015). This process has led to the emergence of 'multi-speed membership' parties which offer a wide array of possible affiliations for members that can vary in its intensity (Scarrow 2015). Moreover, some parties do not restrict access to intra-party democracy to members or voters. Instead, in an attempt to create democratic linkage, they open up the internal decision-making process to individuals without any formal or informal ties to the party.

The second question is how to organize intra-party democracy. The literature makes a distinction between "plebiscitary" and "assembly-based" initiatives. Plebiscitary forms of intra-party democracy have become more widespread since the 1990s promoting 'direct' decision-making in the form of one-member-one-vote procedures (Poguntke et al. 2016: 671; Von dem Berge and Poguntke 2017, p. 144). They offer members or voters a direct say in party decisions through a direct vote in intra-party elections. Assembly based forms of intra-party democracy are aimed at fostering discussion and debate within party bodies. They are less 'vote-centric' and 
"require the temporal coincidence of discussion and decision" (Von dem Berge and Poguntke 2017, p. 144) which brings them closer to the ideal of deliberation.

The third and final question relates to the finality of intra-party democracy. Parties play many roles in a democratic system but two of them stand out. On the one hand, intra-party democracy can be used in the recruitment process of political personnel. Supporters are then allowed to assist in the selection and nomination of the party leadership but also in the process of candidate selection. On the other hand, parties are also involved in the development and formulation of policies. Intra-party democracy then serves the purpose of interest aggregation and articulation, and supporters get the chance of weighing on the substantive position of the party (Loxbo 2013; Rahat and Shapira 2017). Studies have, however, shown that parties are more likely to invite supporters to participate in the election of political personnel such as the party leader or candidates than in the development of party policies (Gauja 2013).

Hence, we can expect parties that explicitly aim to generate legitimate policies by involving a wide variety of actors in deliberation to strive to involve both members, voters, and the general public in assembly based types of engagement. Moreover, in order to apply deliberation to the fullest, we expect that Agora will also try to involve their supporters both in the process of personnel selection and in program development.

\section{Resources}

Finally, a party's organization is also determined by its reliance on organizational resources, which can take many forms but the two most important resources are arguably financial and personnel resources (Scarrow et al. 2017). The amount of financial resources available to a party determines how much (paid) staff they can hire, their material resources, and how much money they can spend during election times. In general, parties are financially better-off when they are well-established, electorally successful, and operate in a relatively sizeable and wealthier country (Poguntke et al. 2016).

The personnel resources of a party consist of its staff and its volunteering members (Van Haute and Gauja 2015). Parties' professional staff consists of its paid employees, who fulfill a pivotal role in a modern party organization that is increasingly dependent on professional expertise (Poguntke et al. 2016). At the same time, the numbers of volunteering party members seem to be dwindling (Scarrow 2015; Van Haute and Gauja 2015). Cartel parties have come to rely more on state funding and bureaucratic power, and less on membership volunteers (Katz and Mair 2018). As they move closer to the state, parties get wealthier and hire more professionals but have become more dissociated from society. Volunteers play an increasingly limited role, especially in the internal organization and day-to-day activities of the party. However, they continue to play an important role during elections times when they are employed as campaigners and social-media multipliers (Scarrow 2015).

Given that party resources are increasingly subject to regulation by the state (Katz and Mair 2018), it is likely that new parties adopting deliberative practices face the 
same conditions as established parties. However, the fact that they are new parties, with often limited representation in parliaments and limited access to bureaucratic networks, makes it likely that they are vulnerable in terms of funding by the state and the reliance on paid professional staff. Like movement parties, they might need to rely on volunteers' durable yet unpredictable engagement and find ways to fund themselves outside of the state (Della Porta et al. 2017). Since Agora is a new party, which grew out of a movement, we expect that its volunteers will be its most important asset, but also that its volunteers will be a more unpredictable resource than employees. Moreover, we expect that Agora will try to find creative ways to fund themselves outside of the state.

\section{Case, data and methods}

To explore how parties promoting deliberative practices are organized and function in a representative setting, we analyze the newly founded Brussels party Agora. In 2018, Agora was founded as a citizens' movement with the sole programmatic aim of institutionalizing the permanent Brussels Citizens' Assembly with legislative power (Agora 2021; Bruzz 2019). To realize their democratic ambition, they needed political power. Although Agora's members do not describe their organization as such, Agora became a de facto political party in the minimal electoral definition of the word (Sartori 2005, p. 57) by presenting a list to the 2019 Brussels regional elections and obtaining one seat in the Brussels Parliament. After getting elected, in an experience reminiscent to Green parties (Frankland et al. 2008; Rihoux 2016), Agora needed to become more flexible, responsive, and efficient. The emergence of Agora as a party also introduced a more pragmatic mindset within the larger movement which differs from its more revolutionary origins. Nevertheless, their foundational aim of introducing deliberation at the heart of the representative system remains firmly in place.

Agora can be considered an extreme case of a political party that incorporates deliberative practices (Seawright and Gerring 2008) because it considers deliberation not just a means but as an end in itself. Agora wants to use deliberative techniques to influence the policies of the Brussels government, however, its sole programmatic aim is to install a permanent deliberative citizens' assembly in Brussels. As an extreme case, Agora is ideally suited to explore how a party that pushes the deliberative logic to its limits organizes itself in a representative context and what limitations and tensions this provokes.

In terms of size, Agora is still a marginal party within the Brussels party system, let alone in Belgium. To obtain a seat in parliament, Agora deliberately presented itself on the list for Dutch-speaking voters since this constitutes a minority within the Brussels region with a fixed amount of 17 seats resulting in an overrepresentation of Dutch-speaking voters in the Brussels Parliament compared to the 72 seats for the French-speaking voters. Although Agora is a multilingual party with mostly French-speaking members and volunteers, presenting themselves on the Dutchspeaking list made gaining a seat less competitive. This resulted in an election result of 3.629 votes of the 69.996 Dutch-speaking voters. This was just above the 
Table 1 Background of the interviewees

\begin{tabular}{lr}
\hline Gender & $n$ \\
\hline Male & 10 \\
Female & 10 \\
Age & \\
$18-35$ & 15 \\
$36-59$ & 4 \\
$60+$ & 1 \\
Seniority & \\
Less than a year & 10 \\
A year (i.e. since the start) & 10 \\
Language & \\
French & 13 \\
Dutch & 4 \\
Other & 3 \\
\hline
\end{tabular}

5\% electoral threshold and made them the party with the least votes in the Brussels regional Parliament. The Brussels Parliament is competent for regional matters that vary from urban planning to foreign trade. Furthermore, elected politicians also sit in the Council of the Flemish Community Commission or French Community Commission depending on which language list they are elected. These commissions are competent for cultural matters such as education but also health and welfare. Hence, the regional levels in Belgium have important competencies and its ordinances have in principle the same value as federal laws. The empirical results regarding the functioning of democratic practices within a political party should be interpreted bearing this context in mind and are, given the 'extreme case study', difficult to generalize.

We studied the party website, its manifesto, internal documents, and conducted 20 in-depth semi-structured interviews with party members and affiliates. We purposively sampled respondents to reflect a variety of age, gender, language, and seniority. $^{2}$ Even though we relied on a snowball strategy, we carefully selected members from the party's various working groups to tap into the large variety of experiences within Agora. Table 1 provides an overview of the background of the interviewees. ${ }^{3}$ The overrepresentation of young French speakers matches well with the composition of Agora as described in interviews and documents. Agora's membership base has a remarkable age gap compared to most other parties which are dominated by older men (Van Haute and Gauja 2015).

The interviews were conducted from April to July 2020. The appendix offers an overview of the anonymized interviewees and their dates. Since the group of people

\footnotetext{
${ }^{2}$ We allowed our sampling strategy to adapt to new insights after the first interviews. This permitted us to sample relevant cleavages within the party. For instance, the importance of seniority (i.e. those who founded the party versus those who joined later on) only became clear after a couple of interviews.

3 Initially, we planned to sample respondents based on their level of education; however, we dropped this criterion at a later stage since we couldn't identify any lower educated party members.
} 
involved in Agora is relatively small, we cannot offer more information on other identity features of the respondents without compromising their anonymity. ${ }^{4} \mathrm{We}$ adopted a semi-structured approach and the interview guide reflected the relevant dimensions of our conceptual framework, i.e. the party's organizational structure, its intra-party democracy, and its resources.

The analysis was conducted in NVivo by two researchers, and followed a thematic analysis approach structured in two main steps (Boyatzis 1998; Fereday and MuirCochrane 2006). We triangulated data from the party website, party documents, and interviews is useful to get a good understanding of the party's formal (written) rules on the one hand and the unwritten, informal practices and norms at play on the other hand (Evans and Kenny 2019). More information about the interviewing and coding process can be found in the appendix.

\section{Empirical findings}

\section{Agora's blueprint}

To outline how Agora's aim of promoting deliberation is put into practice, we first introduce Agora's organization through a description of the entities of the party. Agora consists of three main entities.

The first entity is the Movement ${ }^{5}$ which consists of eight working groups. They divide the organizational tasks and responsibilities amongst each other. The Movement has been organized in working groups since its inception. However, some working groups were established at a later stage, such as the legal working group that was established to support the party-in-parliament. The Movement consists of employees, volunteers, and sympathizers. It is responsible for the practical organization of the party, provides support to the MP, and organizes the Citizens' Assembly. The Movement also acts as an auditing institution and scrutinizes the work of the MP to make sure he stays within the contours of his political mandate. Finally, the Movement is also responsible for composing the candidate list during elections and to promote deliberation in the broader public sphere. The Inter Working group (InterWG), where all working groups meet monthly, decides upon important strategic matters. The Forum, where representatives of all working groups meet biweekly, coordinates the daily management of the party. The composition of these bodies varies strongly over time. Working groups regularly appoint a new representative. The Forum is supported by the secretariat whose task is to prepare the Forum.

\footnotetext{
${ }^{4}$ Due to the COVID-19 pandemic and the social distancing rules that applied in Belgium, we conducted most interviews digitally (Skype, Zoom, etc.). All interviews were audio-recorded after having obtained the informed consent of the interviewees and then transcribed. Most interviews ranged from one hour to two hours.

5 The initial movement morphed into a party when Agora started to participate in the Brussels' regional elections. At the same time, Agora members continued to refer to the working groups as a "Movement". Unsurprisingly, this is often the case in movement parties (see for instance Della Porta et al., 2017).
} 
The second entity is the elected MP in the Brussels Parliament and his team. The $M P$ is Agora's face in parliament and functions as the liaison between the Citizen's Assembly and the Brussels Parliament. The MP votes and proposes the Assembly's recommendations, votes upon and proposes issues regarding democratic renewal, and 'enlightens' other MP's in the Brussels Parliament about the value of democratic innovations.

The Citizens' Assembly is Agora's third and final entity. It consists of 89 randomly selected citizens from Brussels who are appointed for one year. At the end of every year, they formulate recommendations which the MP transfers to the parliament. The Citizens' Assembly has the main formal political decision-making power within Agora in the sense that only this body decides how the party votes in parliament except for issues regarding democratic renewal in which the MP can freely promote democratic innovations. While the Assembly remained relatively diverse it was difficult to avoid dropout among lower educated members.

\section{Structure}

The description of the party's blueprint has already unveiled some of its organizational structure. However, a deeper analysis reveals an organizational structure that (1) strongly restricts leadership autonomy and (2) imposes a type of stratarchical decentralization.

While the party consists of three clearly delineated entities, Agora has not defined any formal party leadership. Most of the policy-making powers lie with the Citizens' Assembly. At first sight this might not seem unusual since most established and new parties have representative assemblies or party congresses consisting of members with formal decision-making power in important party matters (Scarrow 2015). However, Agora's Assembly is exceptional since it consists not of members but of randomly selected citizens. In other words, individuals without formal ties to the party are given a central say in the policies the party should promote. In contrast, the Movement and the MP (i.e. those closest to the party) are considered politically inferior to the Citizens' Assembly. This means that Agora-as a party promoting deliberation - has implemented a reversal of power compared to traditional mass parties: those organizationally and/or ideologically closest to the party have significantly restricted powers.

It should nonetheless be noted that the autonomy of the Citizens' Assembly is not absolute neither. In principle, the will of the Assembly reigns supreme but in some circumstances it can be counterbalanced by other entities in the party. A generally agreed upon principle is that the Movement can counterbalance the Citizen's Assembly in dialogue with its MP or its parliamentary team if the Citizens' Assembly's proposals violate the constitution, human rights or the rule of law. As one member puts it:

For me, it was evident that it was necessary to create a system of internal control, with the possibility of rejecting certain citizen proposals. We concluded that we should limit ourselves to human rights and the constitution. - Respondent 4 


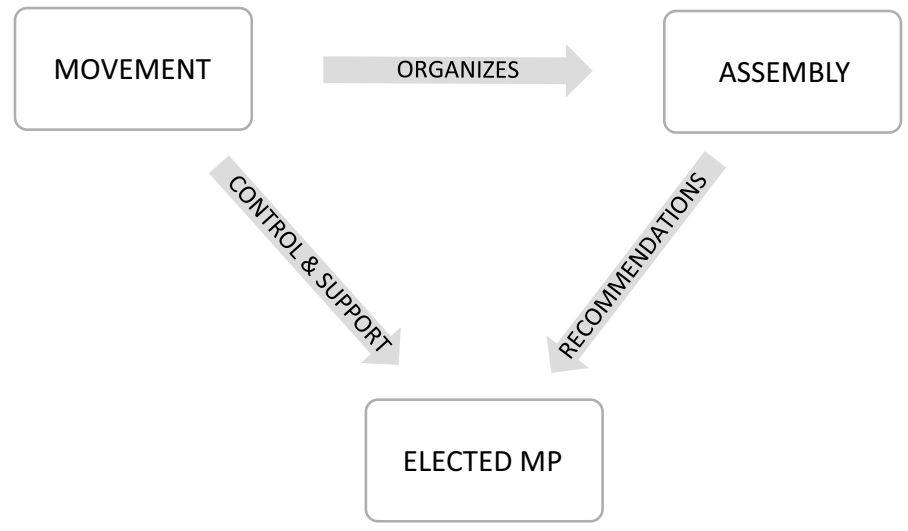

Fig. 1 Agora's organizational structure

Apart from this, the power and autonomy of the working groups and the MP are limited. On the face of it, the MP, who is externally the most visible person within the party, could be considered the party's leadership figure. However, Agora's statutes stipulate that having an elected MP is merely a temporary and necessary evil to introduce the Citizen's Assembly's proposals in parliament. It is a means to an end and the MP's powers are by and large limited to this transfer of ideas. In the interviews, the MP was also presented as a direct and extreme delegate of the Citizen's Assembly who does not take any substantive positions apart from the one determined by the Assembly. There are two notable exceptions. First, the MP is allowed to advocate policies that are in line with a more deliberative and participatory Brussels' public sphere. The second exception is that the proposals of the Assembly need to stay within the framework of human rights and the rule of law. If they fail to oblige by these standards the MP will not defend them in parliament. This did not yet happen. Analyzing parliamentary documents, we find that the MP does not deviate from these principles and abstains from all other votes.

Agora's restrictions on the leadership's autonomy is paralleled by a rather decentralized organization. The relationship between Agora's entities is stratarchical rather than hierarchical (Carty 2004; Cross 2018; Bolleyer 2012). While one must think about stratarchy in terms of degree rather than in absolute categories (see Bolleyer 2012), our analysis shows that Agora closely approaches ideal stratarchy. All entities and members in Agora operate relatively autonomously within their discursively constructed mandate while depending on each other. The MP, the working groups, and the main entities enjoy a significant degree of autonomy as long as they do not deviate from Agora's overarching goal and strategy to promote deliberative democracy through its assembly. At the same time, the various entities and working groups fulfill different roles and therefore depend on each other to realize Agora's political goals. The stratarchical organization allows the different entities of the party to separate and distribute power to control each other (see Fig. 1). The Movement, the Assembly, and the elected MP depend on each other to function properly 
and actively control and balance each other. One respondent describes the relation as follows:

It would not be tolerated if the MP would deviate from the Assembly's goals. There is a lot of trust and every group functions within its autonomous mandate. However, at the same time there is a constant interaction between the Assembly, the Movement, and our MP. This is normal since they need each other. One cannot function without the other and by interacting with each other in a critical and deliberative way we make sure not to abandon our ideological mission to spread deliberation - Respondent 6

This suggests that the stratarchical separation of power is one factor that renders the party more robust to leadership domination than other parties that adopt deliberative practices such as M5S and Podemos (Ignazi 2021). Due to the stratarchical separation of powers, Agora requires and stimulates deliberation between entities on equal footing. In the case that one entity would abandon Agora's ideological goals in favor of careerists and instrumental goals, the other entities can counterbalance these tendencies. After all, when power is distributed between autonomous entities it is much harder for a small group of people to control and dominate all entities.

\section{Intra-party democracy}

The second dimension of party organization according to Poguntke et al. (2016) is intra-party democracy. To the extent that notions of party membership have become increasingly complex in recent years (Scarrow 2015), it is clear that any traditional boundaries between members and non-members are even more flawed in the case of Agora. The party itself does not define membership in any formal way. Since the party statutes do not mention any formal definition of membership, everyone can volunteer and contribute to the party's functioning. After attending a couple of meetings, anyone interested can participate and contribute. As a result, formal, feepaying membership takes a backseat, and can be understood as easily accessible, fluid, and experienced at multiple speeds (Gauja 2015; Gomez and Ramiro 2019). Rather than having a straightforward and uniform approach to membership within a statutory remit, various members contribute at different paces in various ways at different times. A member can be at the forefront of the organization one month and disappear to the background the other. Agora members do not necessarily conceive of themselves as members. Their self-conception is rather defined by the precise role they play in the organization at a particular moment in time.

The randomly selected Citizen's Assembly plays a central role in Agora's internal decision-making. Agora distinguishes itself from other parties by the fact that its policy preferences are exclusively assembly-based. The Assembly decides Agora's voting-behavior and positioning in parliament. However, the Assembly has no direct say about the internal organization, the recruitment of political personnel, and the general functioning of Agora as a party. In other words, it defines Agora's policy goals but not how to reach them. 
The assembly is representative and internally inclusive due to experienced facilitation and the composition of the assembly which consists of citizens drawn by lot, with a sampling correction based on gender, age, and participants' level of education. However, this also means that not anyone can freely join the assembly.

Internal matters within the party are settled through deliberation and decision by consent among the people involved. Since there is no formal Agora membership, new supporters can immediately impact the party's internal policy by participating in the party's deliberations. After deliberation, the main device through which decisions are made is by consent, not by vote. When collective decisions need to be taken at any level of the organization, they deliberate with all affected participants until no major objections are left. Every participant in the deliberation has veto power over the decision at stake. Until all participants consent, no decision can be taken:

If someone says, 'I can't live with this decision', we open it up and see if we can refute that person's objection. If the person remains unconvinced, the proposal is rejected and reported to the following InterWG. - Respondent 10

In practice, however, vetoes only rarely occur, since it is assumed that participants do not raise objections out of personal self-interest. In line with early accounts of deliberation, only common good arguments are considered acceptable (Habermas 1989). Participants can only make valid objections if they relate them to the common good and Agora's philosophy. As one participant describes the logic of objections within Agora:

So it's not about an individual look, but a look at the collective. For example, I could be against an idea because it doesn't go with my political ideas. But that doesn't intervene in the process. I have to decide with an eye on the Agora values and the thoughts and ideology of Agora as a group. - Respondent 8

Given all these formal rules and structures, one could conclude that the party is highly inclusive. However, in practice it is not as easy to participate in Agora's organization as it formally seems. Participation in Agora requires significant time and cognitive investment and this is reflected in its membership. Most party members are highly educated and communicate in a way that might be less appealing to lower educated citizens. Moreover, over time the party developed many rules and complicated organizational resources that might be overwhelming to deal with for new members, especially when lacking time and cognitive resources. The case thus shows that a party which is theoretically open to all is not necessarily inclusive in practice.

\section{Resources}

The final dimension of any party organization is its resources. Agora can rely on several financial and personnel, but they are all in all rather limited. The financial resources consist of the MP's salary. The MP himself has agreed to accept the median wage in the Brussels region. The rest is used to fund and support the 
organization of the Citizens' Assembly including the facilitators, attendance fees, lunches, and more. Additionally, the Brussels Regional Parliament provides every MP with a budget to hire parliamentary staff. This budget is distributed among eight employees whom also receive the median wage. It is striking that Agora as a party that seeks to hijack parliament is dependent on funding from the very same parliament they seek to hijack. In this regard, Agora is similar to cartel parties that highly rely on state funding and does not look to be financially autonomous from the state (Katz and Mair 2018).

However, the main thrust of the organizational resources lies with Agora's personnel resources: its volunteers. Even though the contribution of volunteers range from being central to the organization to minimal involvement, they vastly outnumber Agora's professional staff. At the same time, the line between employees and volunteers is blurred at times. While employees are paid, their work and level of involvement do not clearly deviate from the volunteers. Moreover, members differ in their perceptions of what it means to be a volunteer. Some see their roles as secondary and supportive to the employees, while others perceive themselves as initiativetakers. The two quotes below illustrate the clear contrast between the volunteers' perception:

We realize that it is not possible to work as a volunteer and be productive. You have to be an employee to invest a lot of time in Agora. But as a volunteer, you can't give as much, so your input is not huge. It has to remain a supporting role for the members who work full time for Agora. - Respondent 16

It's a little bit similar to other organizations, running for $95 \%$ on volunteers. Which is I would say at least the proportion within Agora. You always have people who are volunteering more than others but we assume that at Agora everything is possible in terms of personal investment. There are no limits, you simply need to motivate yourself. - Respondent 4

In any case, there is a notable contrast between Agora and established parties that have come to rely less on membership volunteers (Katz and Mair 2018). The party is more in tune with movement parties that rely on volunteers to mobilize and organize (Della Porta et al. 2017). The main disadvantage of this model is that it is difficult to keep volunteers engaged in the long run. The interviews show that senior members lament the lack of more stable organizational foundations regarding personal resources as volunteers come and go. Indeed, as other studies have also shown, keeping members invested in a context of maximized inclusion is extremely challenging (see Bolleyer et al. 2015).

\section{The challenge of promoting deliberation in a representative system}

The analysis above has shown that Agora's organizational structure is exceptional, or at least quite different, even compared to other parties embracing deliberative practices. Agora does not define clear leadership positions and it grants significant decision-making power to individuals who are not affiliated with the party. Its organizational structure is best described as a stratarchy with the interactions between the 
strata being assembly based. Agora's organization might seem idiosyncratic but it can only be understood by taking into account Agora's goals of promoting deliberative ideals in a representative system.

gora's organizational choices are a constant attempt at reconciling its programmatic ideals of deliberation with the political context of representation. This balancing act has, however, produced some tensions, not in the least between inclusive and effective decision-making (see Hazan and Rahat 2010; Cross and Katz 2013; Bolleyer et al. 2015 for similar findings). This tension also feeds into Agora's transformation from a grassroots movement to a professional political party. When Agora entered the Brussels parliament, efficacy became more pressing than what the Movement was used to. The need to act quickly and decisively in parliament did not always combine easily with member and citizen consultations which usually required more time. Multiple respondents also indicated that inclusiveness was often difficult to reconcile with effectiveness, especially in a parliamentary context. The MP is an extreme delegate of the Citizens' Assembly but correctly interpreting and representing the recommendations of the Assembly did not prove easy. One member shared the following sentiment:

At first, Agora was purely a movement. But now it is an elected movement that has employees and is linked to a parliament that is organized hierarchically. The way of working has changed a bit as a result. Internally there is no hierarchy, but the outside world in which we must be able to function is hierarchically organized. - Respondent 14

The interactions between the different entities of the party also leads to a tension between pragmatism and radicalism. The party's ultimate goal is to institutionalize a permanent citizens' chamber in the Brussels parliament by the next elections, which would constitute a radical innovation. However, members realize that there is still a long way ahead and the professionalization of the party and its parliamentary experience has introduced a more pragmatist mindset. As soon as the party got elected, radical optimism thus yielded to pragmatic realism.

In other words, Agora's goal is to create an efficient force that can change the system 'from within'. Their official Facebook page mentions that its elected representative in the Brussels Parliament "will not simply take up his seat, but wants to 'hack' the system from within" (Agora.Brussels Facebook page, 11 July 2019). However, 'hacking democracy' might generate intrinsic tensions. The more successful and organized Agora becomes at playing the parliamentary game, the more likely it is that they succeed in their mission to institutionalize a citizens' chamber and to foster meaningful deliberation in the Brussels public sphere. However, the more successful they are, the more difficult it might also become to dismantle the growing organization when its goals are accomplished. The party might end up evolving in a way similar direction as the Greens (Frankland et al. 2008; Rihoux 2016). Their increasingly pragmatist stance towards the representative system might end up inhibiting its radical aims of replacing parliament with a citizen's chamber. It remains to be seen whether Agora's stratarchical organization is robust enough to withstand this challenge. 


\section{Conclusion}

This paper contributes to the emerging literature on the rise of deliberative ideas and practices among and within political parties. Departing from the extreme case of Agora, we investigate how deliberative practices are implemented in a political party and how organizational characteristics allow parties to navigate the troubled waters of promoting deliberation while functioning in representative environment. To this end, we studied Agora's organizational structure, its intraparty democracy, its resources, and, by extension, its tense relationship with the representative system.

Much like other political parties incorporating deliberative practices, Agora has to juggle the competing demands of radicalism and pragmatism on the one hand, and deliberative inclusion and representative efficiency on the other (Hazan and Rahat 2010; Cross and Katz 2013; Bolleyer et al. 2015). To deal with these competing demands, Agora restricts leadership autonomy and adopts a strongly decentralized stratarchical organization in which there exists a complex interplay between mutually autonomous party entities. Moreover, the party is also inclusive because (1) each supporter has an equal say in the party's deliberations and (2) membership is easily accessible, fluid, and occurs at multiple speeds. However, one important limitation to Agora's inclusiveness is that, in practice, membership requires a lot of time and cognitive resources.

Case studies must be interpreted with great care and are notoriously difficult to generalize. Agora's status as a small and unique party in a regional parliament further limits generalization. Nevertheless, as an extreme party that forcefully rejects the representative system and strongly promotes intra-party deliberation, Agora reveals a clear avenue to mitigate the tension between the call for intraparty deliberation and the pull of Michels' (1911) iron law in a representative system. By separating and balancing power, following a stratarchical party template, Agora is relatively successful in promoting meaningful intra-party deliberation while effectively operating in a representative system. This is important since other parties promoting deliberation, such as M5S and Podemos, seem to fall prey to power concentration and leadership domination (Ignazi 2021). Other parties with deliberative and participative ambitions can learn from Agora as an empirical manifestation of Carty's argument $(2004$, p. 9) that a stratarchical organization can be responsive to the imperatives of a competitive representative system as well as to intra-party demands. Our case-study suggests that inclusiveness is more robust and meaningful when applied in a decentralized context. After all, parties that are formally inclusive but highly centralized are more sensitive to elite capture and domination by a few steering agents (Aylott and Bolin 2017). Decentralizing party decision-making makes it harder for elites to dominate the entire party as power is balanced between multiple entities. Hence, adopting a stratarchical division of power between party entities could be an interesting avenue for other parties with deliberative ambitions to avoid elite capture.

Nevertheless, our analysis shows that it is challenging for a party promoting deliberative practices to balance pragmatist means with radical ends even in the 
extremely deliberative case of Agora. By attempting to hijack the representative system, such parties risk gradually becoming part of it. Promoting deliberative ideals according to the representative rule book shapes and constrains Agora's external promotion of deliberative democracy.

Supplementary Information The online version contains supplementary material available at https://doi. org/10.1057/s41269-021-00226-3.

\section{Declarations}

Conflict of interest On behalf of all authors, the corresponding author states that there is no conflict of interest.

\section{References}

Aylott, N., and N. Bolin. 2017. Managed intra-party democracy: Precursory delegation and party leader selection. Party Politics 23 (1): 55-65.

Bächtiger, A., and J. Parkinson. 2019. Mapping and measuring deliberation. Oxford: Oxford University Press.

Barberà, O., and J. Rodríguez-Teruel. 2020. The PSOE's deliberation and democratic innovations in turbulent times for the social democracy. European Political Science 19: 212-221.

Bennett, W.L., A. Segerberg, and C.B. Knüpfer. 2018. The democratic interface. Information, Communication \& Society 21 (11): 1655-1680.

Bolleyer, N. 2012. New party organization in Western Europe. Party Politics 18 (3): 315-336.

Bolleyer, N. 2013. New parties in old party systems. Oxford: Oxford University Press.

Bolleyer, N., C. Little, and F.-C. von Nostitz. 2015. Implementing democratic equality in political parties. Scandinavian Political Studies 38 (2): 158-178.

Boyatzis, R.E. 1998. Transforming qualitative information. Thousand Oaks: Sage.

Bruzz. 2019. Agora mikt op 2 zetels: 'Paard van Troje in parlement'. Interview with P. Kennis, https:// www.bruzz.be/videoreeks/brussel-kiest-de-kandidaten/video-agora-mikt-op-2-zetels-paard-vantroje-parlement. Accessed on 8 September 2020.

Caiani, M., E. Padoan, and B. Marino. 2021. Candidate selection, personalization and different logics of centralization in new Southern European populism. Government and Opposition, published online 8 April 2021.

Carty, R.K. 2004. Parties as franchise systems. Party Politics 10 (1): 5-24.

Cross, W. 2018. Understanding power-sharing within political parties: Stratarchy as mutual interdependence between the party in the centre and the party on the ground. Government and Opposition 53 (2): 205-230.

Cross, W.P., and R.S. Katz. 2013. The challenges of intra-party democracy. Oxford: Oxford University Press.

Dalton, R.J., and M.P. Wattenberg. 2002. Parties without partisans. Oxford: Oxford University Press.

Della Porta, D., et al. 2017. Movement parties against austerity. Cambridge: Polity Press.

Evans, E., and M. Kenny. 2019. The women's equality party. Political Studies 67 (4): 855-871.

Fereday, J., and E. Muir-Cochrane. 2006. Demonstrating rigor using thematic analysis: A hybrid approach of inductive and deductive coding and theme development. International Journal of Qualitative Methods 5 (1): 80-92.

Fisher, J., E. Fieldhouse, and D. Cutts. 2014. Members are not the only fruit. The British Journal of Politics and International Relations 16 (1): 75-95.

Frankland, E.G., P. Lucardie, and B. Rihoux. 2008. Green parties in transition: The end of grass-roots democracy? Surrey: Ashgate Publishing.

Gad, N. 2020. A “new political culture.” European Political Science 19 (2): 190-199.

Gauja, A. 2013. The politics of party policy. Basingstoke: Palgrave Macmillan.

Gauja, A. 2015. The construction of party membership. European Journal of Political Research 54 (2): $232-248$. 
Gherghina, S., S. Soare, and V. Jacquet. 2020. Deliberative democracy and political parties. European Political Science 19 (2): 200-211.

Gomez, R., and L. Ramiro. 2019. The limits of organizational innovation and multi-speed membership. Party Politics 25 (4): 534-546.

Habermas, J. 1989. The Structural Transformation of the Public Sphere. Cambridge, MA: MIT Press.

Hazan, R.Y., and G. Rahat. 2010. Democracy within parties. Oxford: Oxford University Press.

Ignazi, P. 2018. The four knights of intra-party democracy. Party Politics 26 (1): 9-20.

Ignazi, P. 2021. The failure of mainstream parties and the impact of new challenger parties in France, Italy and Spain. Italian Political Science Review 51 (1): 100-116.

Katz, R., and P. Mair. 2018. Democracy and the cartelization of political parties. Oxford: Oxford University Press.

Loxbo, K. 2013. The fate of intra-party democracy. Party Politics 19 (4): 537-554.

Mosca, L. 2020. Democratic vision and online participatory spaces in the Italian Movimento 5 Stelle. Acta Politica 55 (1): 1-18.

Passarelli, G., ed. 2015. The presidentialization of political parties. New York: Palgrave Macmillan.

Pilet, J.-B., and W. Cross. 2014. The selection of political party leaders in contemporary parliamentary democracies. New York: Routledge.

Poguntke, T., S.E. Scarrow, P. Webb, et al. 2016. Party rules, party resources and the politics of parliamentary democracies. Party Politics 22 (6): 661-678.

Rahat, G., and A. Shapira. 2017. An intra-party democracy index: Theory, design and a demonstration. Parliamentary Affairs 70 (1): 84-110.

Rihoux, B. 2016. Green party organizations. In Green parties in Europe, ed. E. Van Haute, 298-314. London: Routledge.

Sandri, G., and A. Amjahad. 2015. Party membership and Intra-party democracy: How do members react to organizational change within political parties? The case of Belgium. Partecipazione e Conflitto 8 (1): 190-214.

Sandri, G., A. Seddone, and F. Venturino. 2015. Party primaries in comparative perspective. Farnham: Ashgate Publishing.

Sartori, G. 2005. Parties and party systems. A framework for analysis. Colchester: ECPR Press.

Scarrow, S. 2015. Beyond party members: Changing approaches to partisan mobilization. Oxford: Oxford University Press.

Scarrow, S., and P. Webb. 2017. Investigating party organization. Structures, resources, and representative strategies. In Organizing representation, ed. S. Scarrow, P. Webb, and T. Poguntke, 1-27. Oxford: Oxford University Press.

Scarrow, S., P. Webb, and T. Poguntke, eds. 2017. Organizing representation. Oxford: Oxford University Press.

Schumacher, G., and N. Giger. 2017. Who leads the party? Political Studies 65 (1): 162-181.

Seawright, J., and J. Gerring. 2008. Case selection techniques in case study research. Political Research Quarterly 61 (2): 294-308.

Van Biezen, I., P. Mair, and T. Poguntke. 2012. Going, going, ... gone? The decline of party membership in contemporary Europe. European Journal of Political Research 51 (1): 24-56.

Van Haute, E., and A. Gauja. 2015. Party members and activists. London: Routledge.

Van Haute, E., E. Paulis, and V. Sierens. 2018. Assessing party membership figures. European Political Science 17 (3): 366-377.

Van Spanje, J. 2018. Controlling the electoral marketplace. Basingstoke: Palgrave.

Vodová, P., and P. Voda. 2020. The effects of deliberation in Czech Pirate Party. European Political Science 19 (2): 181-189.

von dem Berge, B., and T. Poguntke. 2017. Varieties of intra-party democracy. In Organizing representation, ed. S. Scarrow, P. Webb, and T. Poguntke, 136-157. Oxford: Oxford University Press.

Wauters, B. 2014. Democratizing party leadership selection in Belgium. Political Studies 62 (1): 61-80.

Wolkenstein, F. 2016. A deliberative model of intra-party democracy. Journal of Political Philosophy 24 (3): $297-320$.

Wolkenstein, F. 2018. Intra-party democracy beyond aggregation. Party Politics 24 (4): 323-334.

Publisher's Note Springer Nature remains neutral with regard to jurisdictional claims in published maps and institutional affiliations. 